\title{
Decision-Support System for Urban Air Pollution under Future Climate Conditions
}

\author{
Steen Solvang Jensen ${ }^{1}$, Jørgen Brandt ${ }^{1}$, Martin Hvidberg ${ }^{1}$, Matthias Ketzel ${ }^{1}$, \\ Gitte Brandt Hedegaard ${ }^{1,2}$, and Jens Hesselbjerg Christensen ${ }^{2}$ \\ ${ }^{1}$ National Environmental Research Institute (NERI), Department of Atmospheric Environment, \\ Aarhus University, Denmark \\ $\{\mathrm{ssj}, \mathrm{j}$ br , mhv, mke, gbh $\} @ \mathrm{dmu} . \mathrm{dk}$ \\ ${ }^{2}$ Danish Meteorological Institute (DMI), Danish Climate Centre (DKC), Denmark \\ $\{j h c, g b h\} @ d m i . d k$
}

\begin{abstract}
Climate change is expected to influence urban living conditions and challenge the ability of cities to adapt to and mitigate climate change. Urban climates will be faced with elevated temperatures and future climate conditions are expected to cause higher ozone concentrations, increased biogenic emissions from vegetation, changes in the chemistry of the atmosphere and changes in deposition of particulate air pollution. This paper describes a conceptual outline of a decision-support system for assessment of the impacts of climate change on urban climate and air quality, and for assessment of integrated climate change and air pollution adaptation and mitigation strategies.
\end{abstract}

Keywords: Decision-support system; climate change; dynamical downscaling; urban heat island effect; urban air quality; adaptation; mitigation.

\section{Introduction}

Climate change is expected to increase the global temperature, raise the sea level and alter the storm activity and precipitation patterns that give rise to flooding and drought events. These parameters affect urban living conditions and challenge the ability of cities to adapt to and mitigate climate change. Under future climate conditions it is expected that we will have higher ozone concentrations, increased biogenic emissions from vegetation, changes in the chemistry of the atmosphere and changes in how particulate air pollution is washed out of the air or otherwise removed. These changes may pose health risks to the population. Urban climates will be faced with elevated temperatures due to an increased urban heat island effect. At the same time, many cities are growing with challenges in urban, traffic and energy planning in a situation where a low-carbon economy needs to be developed to reduce climate impacts. Continued reductions in air pollution and greenhouse gases are important, as they pose serious threats to both people's health and the environment.

The aim of this paper is to describe a conceptual outline of a decision-support system for assessment of the impacts of climate change on urban climate and air quality, and for assessment of integrated climate change and air pollution adaptation and mitigation strategies. 


\section{System Description}

Figure 1 shows a conceptual outline of sub-models in a decision-support system for assessment of the impacts of climate change on urban climate and air quality, and for integrated assessment of climate change and air pollution adaptation and mitigation strategies.

\section{Decision-support System for Urban Air Pollution under Future Climate Conditions}

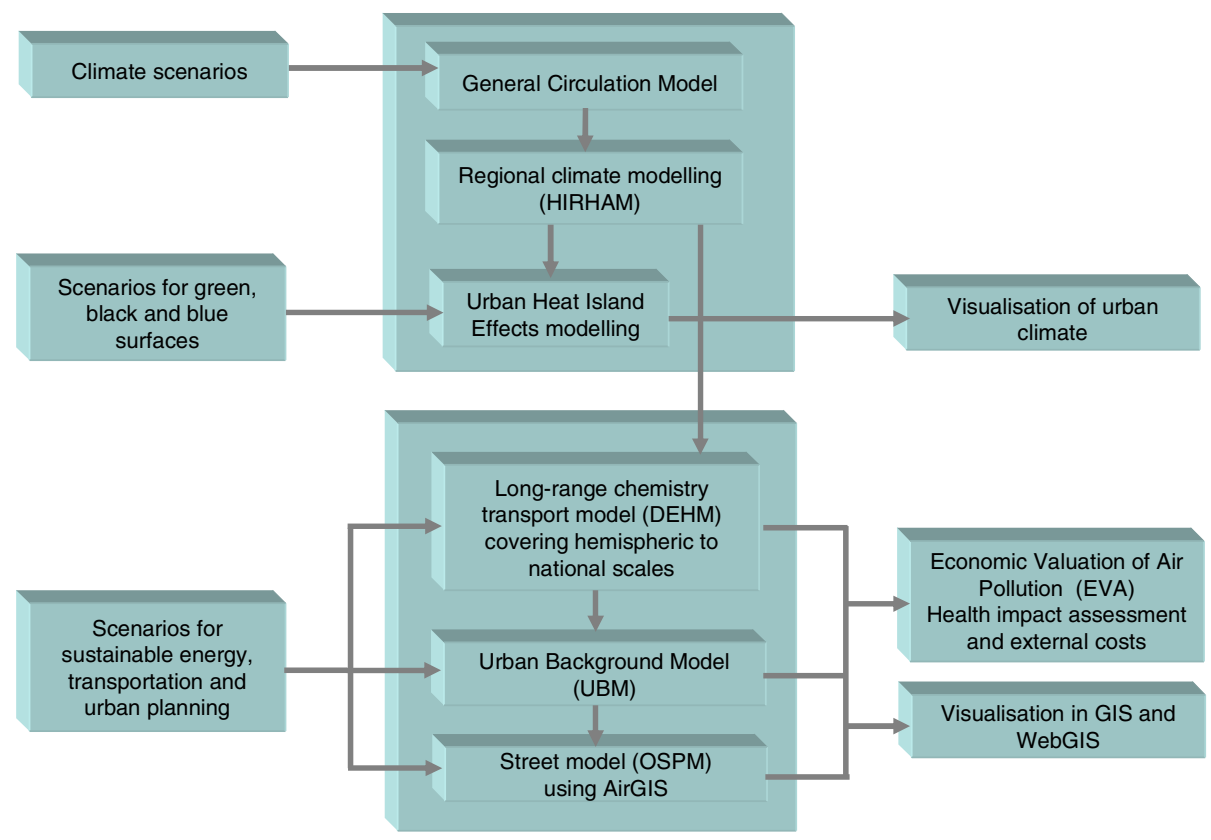

Fig. 1. Conceptual outline of sub-models in a decision-support system for assessment of the impacts of climate change on urban climate and air quality, and for integrated assessment of climate change and air pollution adaptation and mitigation strategies

Dynamic climate downscaling to regional level is based on the HIRHAM regional climate model developed at the Danish Meteorological Institute (DMI). The HIRHAM simulations can then successively be used to simulate Urban Heat island effects by setting up a very high resolution meso-scale model where urban effects are described. This model setup can predict future regional climates under different global climate scenarios, and it can be downscaled to predict future urban climates around the world. Scenarios that target the reduction of urban temperatures can be modelled through adaptation measures.

The air pollution modelling part of the system includes interlinked air quality models to model regional (Danish Eulerian hemispheric Model (DEHM)), urban background (Urban Background Model (UBM)) and street concentrations (Operational Street Pollution Model (OSPM)) developed at National Environmental Research 
Institute (NERI). Regional concentrations represent conditions in rural areas outside cities and are influenced by all sources within a very large region, urban background levels represent the general pollution level in the city e.g. at roof top level in a city or in an urban park and are due to the regional concentrations including the urban increment from urban sources, and street concentrations include the urban background concentrations and the street increment due to vehicle sources in the street.

The Danish Eulerian Hemispheric Model (DEHM) provides predictions of future regional air quality based on meteorological predictions from the climate model and based on future emission scenarios to obtain certain climate conditions. This model covers the Northern hemisphere.

Urban background modelling may be based on the Urban Background Model (UBM), and modelling of street concentrations by the Operational Street Pollution Model (OSPM). Mapping of air quality at street scale for en entire city can be carried out by the AirGIS system. AirGIS is able to generate street configuration and traffic data for the OSPM model based on digital maps and databases that enables estimation of air quality levels at a large number of addresses in an automatic and effective way. The impacts to future air quality on urban and street scale can be evaluated for different emission scenarios e.g. scenarios on sustainable energy system, fuel and technology changes in road transportation, urban planning etc.

Health impact assessment and assessment of the external costs of air pollution are based on the EVA-system (Economic Valuation of Air Pollution) developed by NERI. External costs included are the costs associated to the health effects of air pollution. In a cost-benefit analyse of different policy options the EVA-system will provide the benefits (reduced costs) of reductions in emissions. The air pollution part of the EVA-system is based on the DEHM and UBM models and hence provides assessment of external costs at the regional and urban background level.

\section{System Features}

The decision-support system includes the following features:

(a) Climate and air pollution models that will enable simulation of changes to regional climate and air quality at different spatial scales under different future climate scenarios.

(b) Assessment of the impacts on regional as well as urban climate with focus on modelling of the urban heat island effect causing significantly warmer metropolitan areas than surrounding rural areas.

(c) Modelling and assessment of air quality; health impacts and associated external costs of air pollution as input to cost-benefit analysis of different policy options.

(d) Impact assessment of climate change adaptation measures to urban heat island effects (e.g. changes in black (asphalt, concrete etc.), green (vegatative) and blue (water) surfaces).

(e) Impact assessment of mitigation measures within urban and traffic planning and sustainable low-carbon energy utilisation as a basis for identification of optimal integrated climate change and air pollution mitigation scenarios. 
(f) Visualisation of emissions, air quality and urban climate on different geographic scales using GIS. Relevant data may also be visualised using WebGIS for internet dissemination of results in a user friendly and interactive way to the general public.

\section{Sub-Models}

\subsection{Regional Climate Modelling}

Increasingly reliable regional climate change projections are now available for many regions of the world due to advances in modelling and understanding of the physical processes of the climate system. Atmosphere-Ocean General Circulation Models (AOGCMs) remain the foundation for projections while downscaling techniques now provide valuable additional detail e.g. [8] [9] [25]. GCMs cannot provide information at scales finer than their computational grid (typically of the order of $200 \mathrm{~km}$ ) and processes at the unresolved scales are important. Providing information at finer scales can be achieved through using high resolution in dynamical models or empirical statistical downscaling. Development of downscaling methodologies remains an important focus and downscaled climate change projections tailored to specific needs are only now starting to become available [11] [15]. Here we propose to use a chain of models, where a GCM is the first link in the chain. These relatively coarse resolution simulations are then providing lateral boundary conditions for a dynamical downscaling set up with the regional climate model HIRHAM [10]. Information originating from the GCM about atmospheric temperature, moisture content, wind and surface pressure is passed to the regional model every 6 hours at the lateral boundary as is sea surface conditions (temperature and sea ice if present), except this information only is updated once per day.

The HIRHAM model has been applied in such a set-up for many regions of the world, including Europe, North America, the Arctic, Africa and East Asia e.g. [9] [26] [24]. Different resolutions have been applied including very high resolution (e.g. $5 \mathrm{~km}$ ) and experiments have been performed that spanning periods up to 150 years.

The HIRHAM simulations can then successively be used to simulate Urban Heat Island effects by setting up a very high resolution meso-scale model ( $\sim 1 \mathrm{~km}$ horizontal grid scale), where urban effects are described or parameterized.

\subsection{Urban Heat Island Effect Modelling}

The modified land surface in cities affects the storage and radiative and turbulent transfers of heat and its partition into sensible and latent components. The relative warmth of a city compared with surrounding rural areas, known as the urban heat island (UHI) effect, arises from these changes and may also be affected by changes in water runoff, pollution and aerosols. Urban heat island effects are often very localised and depend on local climate factors such as windiness and cloudiness (which in turn depend on season), and on proximity to the sea. From a modelling perspective, it is simple to assess the importance of an urban heat island. Experiments can be designed and performed in which different surface characteristics describing the urban area is introduced. This will allow for a detection of the localized UHI effect as well as more remote influences, which may be of some importance if the urban site is a mega-city 
or consists of a larger conglomerate of several major cities. An increase of surface temperatures up to $5-10^{\circ} \mathrm{C}$ have been reported as the effect of UHI in US [28].

Methods of monitoring and modelling UHI must involve mapping of land cover. Most methods use mapping by remote sensing of mainly two parameters that can roughly be categorized as 'black surfaces' and 'green surfaces'. Black surfaces are not all black, but characterised by having 'black body' like radiation reflection and emissivity. These are typically asphalt, concrete, and various roof materials that all are good absorbers of solar radiation and mostly with high heat capacity. Green surfaces are often reflected by a vegetation index, e.g. NDVI. This parameter describes the surface cover photosynthetic properties, and is a proxy for vegetation cooling by evapotranspiration. 'Blue surfaces' (water faces) also have UHI properties highly different from black surfaces, and should be included in any modelling if present. If available, thermal infra-red images of night time surface temperatures can contribute considerably to local understanding and will potentially increase model accuracy. All relevant parameters can be retrieved from commercially available satellite images.

Measures against increasing UHI includes mainly vegetation, and with less effect, the use of lighter-coloured materials. The use of 'green roofs' has a cooling effect and also a positive effect in case of extreme precipitation events. Trees and larger plants can also cast shadow as well as contribute with transpiration. 'Living roofs offer greater cooling per unit area than light surfaces, but less cooling per unit area than curbside planting' [27]. Optimally the combined use of vegetation and materials with favourable reflective, emissive and heat capacity properties should be considered.

\subsection{Regional Air Quality Modelling}

The Danish Eulerian Hemispheric Model (DEHM) is a three-dimensional, offline, large-scale, Eulerian, atmospheric transport and chemistry model developed to study long-range transport of air pollution in the Northern Hemisphere and Europe [4] [6] [7] [12] [13]. The model domain covers most of the Northern Hemisphere, discretized in a $96 \times 96$ horizontal grid, using a polar stereographic projection. The projection is true at $60^{\circ}$ north, where the horizontal grid resolutions for the coarse, medium and fine grids are $150 \mathrm{~km} \times 150 \mathrm{~km}, 50 \mathrm{~km} \times 50 \mathrm{~km}$, and $16.67 \mathrm{~km} \times 16.67 \mathrm{~km}$, respectively, using two-way nesting [13]. The vertical grid is defined using the $\sigma$-coordinate system, with 29 vertical layers. The model describes concentration fields of 58 chemical compounds and 9 classes of particulate matter $\left(\mathrm{PM}_{2.5}, \mathrm{PM}_{10}\right.$, TSP, sea-salt < $2.5 \mu \mathrm{m}$, sea-salt $>2.5 \mu \mathrm{m}$, smoke, fresh black carbon, aged black carbon, organic carbon). A total of 122 chemical reactions are included. Furthermore, the model includes options for describing persistent organic pollutants and mercury.

Wet deposition, included in the loss term, is expressed as the product of scavenging coefficients and the concentration. In contrast, dry deposition is solved separately for gases and particles, and deposition rates depend on the land-cover. Emissions are based on several inventories, including EDGAR, GEIA or RCP, retrospective wildfires, ship emissions both around Denmark and globally, and emissions from the EMEP database. The model has undergone an extensive model validation where model results have been validated against measurements from the whole of Europe over a 20 year period. 
To calculate the marginal difference in regional ambient concentration levels due to a specific emission source or sector, DEHM includes a 'tagging' method [5], to examine how specific emission sources influence air pollution levels, without assuming linear behaviour of atmospheric chemistry, and reducing the influence from the numerical noise. This method, used as a basis for the EVA model system (see below) is more precise than taking the difference between two concentration fields. DEHM has been used to study climate change impacts on future air pollution levels by couple the model to climate data [17] [18].

\subsection{Local-Scale Air Quality Modelling}

For urban areas an interlinked modelling approach is implemented that applies the modelled regional climate and air pollution as boundary conditions for local-scale modelling of urban background concentrations that again are boundary conditions for modelling of street concentrations. In this case, urban background concentrations are modelled with the Urban Background Model (UBM) and street concentrations with the Operational Street Pollution Model (OSPM).

Urban background levels are defined to represent conditions at roof top level in a city or in an urban park. Hourly urban background data are modelled with the Urban Background Model (UBM) [3], a simple area source based dispersion model. Contributions from individual gridded area sources are integrated along the wind direction path assuming linear dispersion with the distance to the receptor point. Horizontal dispersion is accounted for by averaging the calculated concentrations over a given wind direction sector that is dependent on the wind speed and centred on the hourly average wind direction. The model includes simple photochemistry to predict $\mathrm{NO}_{2}$ formation, and requires inputs on emissions, meteorological data and regional background concentrations, as well as land-cover data to estimate surface roughness. A model region of e.g. $35 \mathrm{~km} \times 50 \mathrm{~km}$ may be defined with a grid resolution of $1 \times 1$ $\mathrm{km}^{2}$ for emission inputs for vehicle emissions that is a major source in larger urban areas. Contributions from sources other than vehicles may also be taken into account including industries, space heating, non-road etc.

Concentration levels within the street canyons are calculated with the Operational Street Pollution Model (OSPM) [2]. The calculation points are chosen so as to be representative of locations in front of the buildings at user-specified heights. The OSPM requires information about street geometry (e.g. street orientation, street width, building height in wind sectors), hourly traffic emissions, meteorological parameters and urban background concentrations. The model computes pollution levels as the sum of the direct contribution from traffic and the contribution from the windgenerated recirculation of air pollution inside the street environment. The direct contribution is described by a plume dispersion model and the recirculation contribution by a box model that takes into account the exchange with the urban background air. The influence of traffic induced turbulence is taken into account and it is especially important for low wind speeds. Traffic induced turbulence depends on vehicle density in the street, horizontal area occupied by vehicles and vehicle speed. The model also includes simple photochemistry involving $\mathrm{NO}, \mathrm{NO}_{2}$ and $\mathrm{O}_{3}$ for estimation of $\mathrm{NO}_{2}$ concentrations. The OSPM model has been successfully tested against monitor stations in Denmark, other European countries and in US and Asia [22]. 
The AirGIS system is a deterministic exposure model system based on the OSPM model and urban background concentrations (UBM model) together with digital maps, register data, traffic data, and Geographic Information Systems (GIS) for estimation of air pollution and human exposure in urban areas [19] [20]. One of the unique features of AirGIS is that it is able to generate street configuration and traffic data for the OSPM model based on digital maps on road links with traffic data and building footprints with building heights. This enables estimation of air quality levels at a large number of street locations in an automatic and effective way in urban areas [23].

Demonstration of linked modelling of regional, urban background and street air quality has been shown in studies for short-term forecasts [4], as well as for future air quality assessment under climate mitigation measures with focus on utilisation of hydrogen [21] and biofuels in road transportation [16].

\subsection{Economic Evaluation of Air Pollution}

The concept of the integrated EVA (Economic Valuation of Air pollution) model system is based on the impact pathway chain [1] [14] [5]. The site-specific emissions are causing (via atmospheric transport and chemistry) a concentration distribution, which together with detailed population data is used to estimate the population-level exposure. Using exposure-response functions for health impacts and economic valuations, the exposure is transformed into impacts on human health and related external costs.

The EVA system consists of the regional-scale air pollution model DEHM, address-level or gridded population data, exposure-response functions and economic valuations of the impacts from air pollution. The essential idea behind the EVA system is that state-of-the-art methods are used in all the individual parts of the impact-pathway chain. Other comparable systems commonly use linear source-receptor relationships, which do not accurately describe non-linear processes such as atmospheric chemistry and deposition. The EVA system has the advantage that it describes such processes using a comprehensive, state-of-the-art chemical transport model when calculating how specific changes to emissions affect air pollution levels. All scenarios are run individually and not estimated using linear extra-/interpolation from standard reductions.

The EVA-system is able to estimate the external costs of health-related air pollution based on e.g. emission reduction scenarios. In a cost-benefit analyse of different policy options the EVA-system will provide the benefits (reduced costs) of reductions in emissions.

\section{Conclusion}

A conceptual outline has been presented of a decision-support system for assessment of the impacts of climate change on urban climate and air quality, and for assessment of integrated climate change and air pollution adaptation and mitigation strategies. The model system includes dynamic climate downscaling to regional level under 
different future global climate scenarios as well as subsequent Urban Heat Island effect modelling. The air pollution modelling part of the system includes interlinked air quality models to model regional, urban background and street concentrations. The regional concentrations are based on meteorological predictions from the climate model and on associated future emission scenarios. Health impact assessment and assessment of the external costs of air pollution are also estimated and may provide input to cost-benefit analyse of different policy options.

The impacts to future air quality on urban and street scale can be evaluated for different emission scenarios e.g. scenarios on sustainable energy systems, fuel and technology changes in road transportation, urban planning etc.

\section{References}

1. Andersen, M.S., Frohn, L.M., Brandt, J., Jensen, S.S.: External effects from power production and the treatment of wind energy (and other renewables) in the Danish energy taxation system. In: Deketelaere, K., Milne, J.E., Kreiser, L.A., Ashiabor, H. (eds.) Critical Issues in Environmental Taxation: International and Comparative Perspectives, vol. IV, pp. 319336. Oxford University Press, Oxford (2007)

2. Berkowicz, R.: OSPM - A parameterised street pollution model. Environmental Monitoring and Assessment 65(1/2), 323-331 (2000a)

3. Berkowicz, R.: A simple model for urban background pollution. Environmental Monitoring and Assessment 65(1/2), 259-267 (2000b)

4. Brandt, J., Christensen, J.H., Frohn, L.M., Palmgren, F., Berkowicz, R., Zlatev, Z.: Operational air pollution forecasts from European to local scale. Atmospheric Environment 35(sup. 1), S91-S98 (2001)

5. Brandt, J., Silver, J.D., Frohn, L.M., Christensen, J.H., Andersen, M.S., Bønløkke, J.H., Sigsgaard, T., Geels, C., Gross, A., Hansen, A.B., Hansen, K.M., Hedegaard, G.B., Kaas, E.: Assessment of Health-Cost Externalities of Air Pollution at the National Level using the EVA Model System. CEEH Scientific Report No 3, Centre for Energy, Environment and Health Report series, p. 96 (2011), http: / / www . ceeh. dk

6. Christensen, J.H.: The Danish Eulerian Hemispheric Model - a three-dimensional air pollution model used for the Arctic. Atmospheric Environment 31, 4169-4191 (1997)

7. Christensen, J.H., Brandt, J., Frohn, L.M., Skov, H.: Modelling of mercury in the Arctic with the Danish Eulerian Hemispheric Model. Atmospheric Chemistry and Physics 4, 2251-2257 (2004)

8. Christensen, J.H., Carter, T.R., Rummukainen, M., Amanatidis, G.: Evaluating the performance and utility of regional climate models: the PRUDENCE project. Climatic Change 81(supl. 1), 1-6 (2007), doi:10.1007/s10584-006-9211-6

9. Christensen, J.H., Christensen, O.B.: A summary of the PRUDENCE model projections of changes in European climate by the end of this century. Climatic Change 81(supl. 1), 7-30 (2007), doi:10.1007/s10584-006-9210-7

10. Christensen, O.B., Drews, M., Christensen, J.H., Dethloff, K., Ketelsen, K., Hebestadt, I., Rinke, A.: The HIRHAM Regional Climate Model. Version 5. DMI Technical Report No. 06-17. [Available from DMI, Lyngbyvej 100, Copenhagen Ø, DENMARK] (2006)

11. CORDEX, cited as 2010, http://copes.ipsl.jussieu.fr/RCD_CORDEX.html 
12. Frohn, L.M., Christensen, J.H., Brandt, J., Hertel, O.: Development of a high resolution nested air pollution model for studying air pollution in Denmark. Physics and Chemistry of the Earth 26, 769-774 (2001)

13. Frohn, L.M., Christensen, J.H., Brandt, J.: Development of a high resolution nested air pollution model - the numerical approach. Journal of Computational Physics 179, 68-94 (2002)

14. Frohn, L.M., Andersen, M.S., Geels, C., Brandt, J., Christensen, J.H., Hansen, K.M., Nielsen, J.S., Hertel, O., Skjøth, C.A., Madsen, P.V.: EVA - An integrated model system for assessing external costs related to air pollution emissions. In: A contribution to ACCENT T\&TP, Proceedings from the 2nd ACCENT Symposium, p. 10 (2007)

15. Giorgi, F., Jones, C., Asrar, G.: Addressing climate information needs at the regional level: The CORDEX framework. WMO Bulletin 58, 3 (2009)

16. Gross, A., Jensen, S.S., Brandt, J., Christensen, J.H., Ketzel, M., Frohn, L.M., Geels, C., Hansen, A.B., Hansen, K.M., Hedegaard, G.B., Silver, J.D., Skjøth, C.A.: Regional Air Quality Assessment of Biofuel Scenarios in the Road Transport Sector. In: International Conference on Energy, Environment and Health, - Optimisation of Future Energy Systems, Carlsberg Academy, Copenhagen, Denmark, May 31-June 2 (2010)

17. Hedegaard, G.B., Brandt, J., Christensen, J.H., Frohn, L.M., Geels, C., Hansen, K.M.: Impacts of climate change on air pollution levels in the Northern Hemisphere with special focus on Europe and the Arctic. Atmospheric Chemistry and Physics 8, 3337-3367 (2008)

18. Hedegaard, G.B., Gross, A., Christensen, J.H., May, W., Skov, H., Geels, C., Hansen, K.M., Brandt, J.: Modelling the Modelling the Impacts of Climate Change on Tropospheric Ozone over three Centuries. Atmospheric Chemistry and Physics Discuss 11, 6805-6843 (2011)

19. Jensen, S.S., Berkowicz, R., Hansen, H.S., Hertel, O.: A Danish decision-support GIS tool for management of urban air quality and human exposures. Transportation Research Part D: Transport and Environment 6(4), 229-241 (2001)

20. Jensen, S.S., Larson, T., Kaufman, J., Kc, D.: Modeling Traffic Air pollution in Street Canyons in New York City for Intra-urban Exposure Assessment in the US Multi-Ethnic Study of Atherosclerosis. Atmospheric Environment 43, 4544-4556 (2009), http://dx.doi.org/10.1016/j.atmosenv.2009.06.042

21. Jensen, S.S., Ketzel, M., Brandt, J., Frohn, L.M., Winther, M., Nielsen, O.-K., Jørgensen, K., Karlsson, K.: Impacts of large-scale introduction of hydrogen in the road transport sector on urban air pollution and human exposure in Copenhagen. In: International Conference on Energy, Environment and Health, - Optimisation of Future Energy Systems, Carlsberg Academy, Copenhagen, Denmark, May 31-June 2 (2010)

22. Kakosimos, K.E., Hertel, O., Ketzel, M., Berkowicz, R.: Operational Street Pollution Model (OSPM) - a review of performed validation studies, and future prospects. Environmental Chemistry 7, 485-503 (2011)

23. Ketzel, M., Berkowicz, R., Hvidberg, M., Jensen, S.S., Raaschou-Nielsen, O.: Evaluation of AirGIS - a GIS-based air pollution and human exposure modelling system. International Journal for Environment and Pollution (in press, 2011)

24. Kiilsholm, S., Christensen, J.H., Dethloff, K., Rinke, A.: Net accumulation of the Greenland Ice Sheet: Modelling Arctic regional climate change. Geoph. Re. Lett. 30 (2003), doi:10.1029/2002GL015742

25. Kjellström, E., Giorgi, F.: Introduction to special issue. Climate Research 44, 11-119 (2010) 
26. Pan, Z., Christensen, J.H., Arritt, R.W., Gutowski, W.J., Takle, E.S., Otieno, F.: Evaluation of uncertainties in regional climate change simulations. J. Geophys. Res. 106, 1773517752 (2001)

27. Rosenzweig, C., Solecki, W., Parshall, L., Gaffin, S., Lynn, B., Goldberg, R., Cox, J., Hodges, S.: Mitigating New York City's heat island with urban forestry, living roofs, and light surfaces. In: 86th American Meteorological Society Annual Meeting, Atlanta, Georgia, January 31 (2006)

28. Zhang, P., Imhoff, M.L., Wolfe, R.E., Bounoua, L.: Detecting urban heat island drivers in northeast USA cities using MODIS and Landsat products. In: AGU Fall 2010 Meeting (2010) 